\title{
Chemical genomic guided engineering of gamma-valerolactone tolerant yeast
} CrossMark

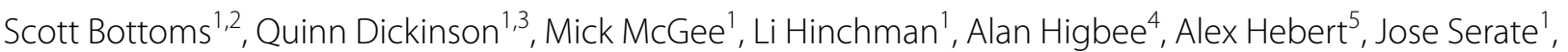 \\ Dan Xie ${ }^{1}$, Yaoping Zhang ${ }^{1}$, Joshua J. Coon ${ }^{5,6,7,8}$, Chad L. Myers ${ }^{9}$, Robert Landick ${ }^{1}$ and Jeff S. Piotrowski ${ }^{1,10^{*}}$
}

\begin{abstract}
Background: Gamma valerolactone (GVL) treatment of lignocellulosic bomass is a promising technology for degradation of biomass for biofuel production; however, GVL is toxic to fermentative microbes. Using a combination of chemical genomics with the yeast (Saccharomyces cerevisiae) deletion collection to identify sensitive and resistant mutants, and chemical proteomics to monitor protein abundance in the presence of GVL, we sought to understand the mechanism toxicity and resistance to GVL with the goal of engineering a GVL-tolerant, xylose-fermenting yeast.

Results: Chemical genomic profiling of GVL predicted that this chemical affects membranes and membrane-bound processes. We show that GVL causes rapid, dose-dependent cell permeability, and is synergistic with ethanol. Chemical genomic profiling of GVL revealed that deletion of the functionally related enzymes Pad1 $p$ and Fdc $1 p$, which act together to decarboxylate cinnamic acid and its derivatives to vinyl forms, increases yeast tolerance to GVL. Further, overexpression of Pad1 $p$ sensitizes cells to GVL toxicity. To improve GVL tolerance, we deleted PAD1 and FDC1 in a xylose-fermenting yeast strain. The modified strain exhibited increased anaerobic growth, sugar utilization, and ethanol production in synthetic hydrolysate with $1.5 \% \mathrm{GVL}$, and under other conditions. Chemical proteomic profiling of the engineered strain revealed that enzymes involved in ergosterol biosynthesis were more abundant in the presence of GVL compared to the background strain. The engineered GVL strain contained greater amounts of ergosterol than the background strain.
\end{abstract}

Conclusions: We found that GVL exerts toxicity to yeast by compromising cellular membranes, and that this toxicity is synergistic with ethanol. Deletion of PAD1 and FDC1 conferred GVL resistance to a xylose-fermenting yeast strain by increasing ergosterol accumulation in aerobically grown cells. The GVL-tolerant strain fermented sugars in the presence of GVL levels that were inhibitory to the unmodified strain. This strain represents a xylose fermenting yeast specifically tailored to GVL produced hydrolysates.

Keywords: Chemical genomics, Gamma-valerolactone, Lignocellulosic, Biofuel, Biocatalysts, Saccharomyces cerevisiae

\section{Background}

Lignocellulosic biomass derived biofuels and commodity chemicals provide a myriad of sustainable bioproducts. Before biomass can be converted to biofuels, it must be first pre-treated and hydrolyzed to fermentable sugars. However, pre-treatment and hydrolysis processes release fermentation inhibitors, which throttle fermentation rates at a substantial economic cost $[1,2]$.

\footnotetext{
*Correspondence: jpiotrowski@yumanity.com

${ }^{10}$ Present Address: Yumanity Therapeutics, 790 Memorial Drive, Suite 2C, Cambridge, MA 02139, USA

Full list of author information is available at the end of the article
}

Fermentation inhibitors come in many forms, and the landscape of these inhibitors is constantly changing as new pre-treatment, hydrolysis, and feedstocks technologies are developed [2]. Enzymatic hydrolysis of biomass releases small acids, phenolics, and furans that are a ubiquitous challenge to bioconversion $[1,3]$. Chemical hydrolysis methods such as $\gamma$-valerolactone (GVL) and ionic liquids offer an enzyme free route to fermentable sugars, but come with their own challenges $[4,5]$. In addition to the biomass-derived inhibitors, the chemicals used for hydrolysis persist in residual amounts in the hydrolysate, and these compounds are known to be 
harmful to fermentative microorganisms [6, 7]. Further, as these chemical catalysts are used in relatively large amounts during hydrolysis, the residual concentrations are often much higher than the small acidic and phenolic inhibitors generated from the biomass.

GVL is the solvent for a promising, new chemical hydrolysis technology to breakdown the cellulose polysaccharides to fermentable sugar monomers [4]. Advantages of GVL include it is recoverable and renewable, as it is a product of biomass conversion. One challenge of this method is the toxicity of residual GVL to fermentative microbes. GVL is mildly toxic to yeast, but this toxicity may be magnified in combination with other inhibitors and the ethanol produced. As such, engineering GVLtolerant microbes is a means of overcoming toxicity, minimizing the costs of reagent recovery, and improving biofuels produced via GVL hydrolysis.

Chemical genomics-guided bioengineering has recently been used to develop yeast strains that are highly tolerant of ionic liquids [8]. Herein, we used chemical genomics to discover the genome-wide response to GVL toxicity. Using this information, we identified specific genes that mediate toxicity, and then engineered these specific mutations into an industrially viable, xylose-fermenting strain of Saccharomyces cerevisiae. This approach offers a rapid method of tailoring existing strains to specific chemical stressors found in industrial bioconversion.

\section{Methods}

\section{Chemicals, strains, growth conditions, toxicity screening and $\mathrm{IC}_{\mathbf{5 0}}$ determination}

Compounds tested were purchased from Sigma, USA. For initial GVL bioactivity tests, cells derived from S. cer-

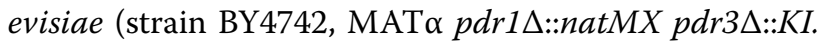

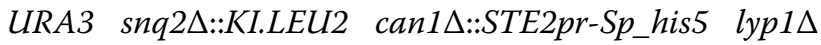
his $3 \Delta 1$ leu $2 \Delta 0$ ura $3 \Delta 0$ met $15 \Delta 0$ ), referred to as the control strain, were grown in $200 \mu \mathrm{L}$ cultures at $30{ }^{\circ} \mathrm{C}$ in YPD, with a drug or DMSO control. Plates were read on a TECAN M1000 over a $48 \mathrm{~h}$ growth period. The specific growth rate was calculated using GCAT analysis software (https://gcat3-pub.glbrc.org/) [9]. When presented, $\mathrm{IC}_{50}$ values for growth inhibition were calculated from triplicate 8-point dose curves and SigmaPlot 12.0. When presented, error bars are Mean \pm Standard error of the mean of at least 3 replicates.

\section{Chemical genomic analysis}

Chemical genomic analysis of GVL was performed as described previously $[8,10]$. The tested yeast deletion collection (created in a derivative of strain BY4742) had $\sim 4000$ strains using the genetic background described in Piotrowski et al. [11]. We grew cells with $2.3 \%$ GVL to mimic the amounts found in GVL produced hydrolysates using $200 \mu \mathrm{L}$ cultures of the pooled, deletion collection of S. cerevisiae deletion mutants was grown in yeast extract $(10 \mathrm{~g} / \mathrm{L})$, peptone $(20 \mathrm{~g} / \mathrm{L})$, and $2 \%$ galactose (YPGal) medium with $2.3 \%$ GVL or a $1 \%$ DMSO control in triplicate for $48 \mathrm{~h}$ at $30^{\circ} \mathrm{C}$. Genomic DNA was extracted using the Epicentre MasterPure ${ }^{\mathrm{TM}}$ Yeast DNA purification kit. Mutant-specific molecular barcodes were amplified with specially designed multiplex primers [11]. The barcodes were sequenced using an Illumina HiSeq. Three replicates of each condition (GVL vs DMSO) were sequenced. The barcode counts for each yeast deletion mutant in the presence of GVL were normalized against the DMSO control conditions to define sensitivity or resistance of individual strains using BEANcounter [12]. To determine a p-value for each top sensitive and resistant mutant, we used the EdgeR package [13, 14]. A Bonferroni-corrected hypergeometric distribution test was used to search for significant enrichment of GO terms among the top sensitive and resistant deletion mutants [15].

\section{MoBY-ORF profiling}

MoBY-ORF profiling of GVL was conducted by first generating a pooled collection of the yeast GLBRC-Y133 (henceforth Y133) containing the plasmid collection [16, 17]. The plasmid pool for transformation was generated as described previously [16]. For yeast transformation, the plasmids were extracted from $150 \mathrm{~mL}$ of $E$. coli culture using a MAXI Prep (Qiagen, USA). Plasmid pools were used to transform Y133 via high efficiency LiAc transformation. Transformed yeast were plated to YPD + G418 agar plates and incubated until colonies appeared. A total of 50,000 colonies were washed from the plates using $1 \times \mathrm{PBS}$, mixed 1:1 with $50 \%$ glycerol, and stored at $-80{ }^{\circ} \mathrm{C}$ until use. For MoBY-ORF profiling, $25 \mathrm{~mL}$ of media containing YPD + 2.5\% GVL+ G418 was allowed to degas overnight in an anaerobic chamber, and then inoculated with $100 \mu \mathrm{L}$ of the transformed yeast pool $(\mathrm{n}=3)$. Cells were grown for $48 \mathrm{~h}$. Genomic DNA was extracted from $1 \mathrm{~mL}$ from each culture using modified mini-prep with zymolyase and glass beads. Gene specific barcodes were amplified, processed, sequenced, and analyzed as described above.

\section{Growth and sugar conversion experiments}

We compared the growth of the Y133 pad1 1 fdc1 $1 \Delta$ to the background strain (Y133) in multiple experimental conditions in flasks: YPXD medium (yeast extract $10 \mathrm{~g} / \mathrm{L}$, peptone $20 \mathrm{~g} / \mathrm{L}$, glucose $20 \mathrm{~g} / \mathrm{L}$, and xylose $20 \mathrm{~g} / \mathrm{L}$ ), with $2.5 \%$ GVL (aerobic) or $2 \%$ GVL (anaerobic, Coy Chamber); anaerobic synthetic hydrolysate $(\mathrm{SynH})$, containing $(60 \mathrm{~g} / \mathrm{L}$ glucose and $30 \mathrm{~g} / \mathrm{L}$ xylose $)+1.5 \%$ GVL [3]; aerobic SynH (90 g/L glucose and $60 \mathrm{~g} / \mathrm{L}$ xylose $)+1 \%$ GVL. For all experiments, cultures were grown in $25 \mathrm{~mL}$ flasks 
$(\mathrm{n}=3)$. Flasks were inoculated with rinsed Y133 or Y133 pad $1 \Delta f d c 1 \Delta$ cells to bring the initial OD to approximately 0.1 . The flasks were grown for $72 \mathrm{~h}$ with agitation anaerobically at $30{ }^{\circ} \mathrm{C} .1 \mathrm{~mL}$ samples were taken every $24 \mathrm{~h}$. Initial and daily samples were measured for OD and submitted for HPLC analysis to quantify sugar consumption and ethanol production [18].

We additionally performed a large scale anaerobic fermentation using 0.5-L bioreactors (BIOSTAT Qplus system from Sartorius, Bohemia, NY, USA) as described in previous work [18]. For these experiments, we used SynH supplemented with $\mathrm{FeSO}_{4}(20 \mu \mathrm{M})$, sodium citrate $(10 \mu \mathrm{M})$, and GVL (1.5\%). Fermentation was done anaerobically by $\mathrm{N}_{2}$ sparging and $\mathrm{pH}$ was controlled at 5 . HPLC samples were collected and analyzed as previously described [18].

\section{Cell leakage assays}

A FungaLight ${ }^{\text {TM }}$ Cell Viability assay (Invitrogen L34952) was used to determine if GVL caused membrane damage we used using a Guava Flow Cytometer (Millipore, USA) as described previously [19]. Briefly, log-phase cultures were incubated with $0,2.5,5$, or $10 \% \mathrm{GVL}$ or $\mathrm{EtOH}$ for $4 \mathrm{~h}$ at $30^{\circ} \mathrm{C}$. The cells were then stained and immediately read by flow cytometry to determine the population of stained cells (permeable) vs non-stained cells.

\section{Synergy screening}

To test for synergy, a $6 \times 6$ dose matrix was initially used to identify potentially synergistic dose combinations, these points were then confirmed in triplicate. $200 \mu \mathrm{L}$ cultures were grown with combinations with GVL (2\%), ethanol (4\%), and the relevant single agent and solvent controls with their OD measured after $24 \mathrm{~h}$. Synergy was determined by comparing actual optical density in the presence of compound combinations to an expected value calculated using the multiplicative hypothesis. This assumes that, in the absence of an interaction, each compound would decrease the OD of the cell culture by the same fraction in the presence of the other compound as it does when applied alone, i.e., $E=A{ }^{*} B / C$, where $E$ is the expected OD, $A$ is OD when compound $\mathrm{A}$ is applied alone, $B$ is OD when compound $\mathrm{B}$ is applied alone, and $C$ is OD of the control culture (DMSO). In the presence of synergy, the actual OD value is lower than the expected OD. A paired t-test was used to confirm statistical significance of this difference in three replicates of the experiment.

\section{Determination of inhibitors present in GVL hydrolysates by RP-HPLC-HR/AM-MMS/MS in GVL hydrolysates}

GVL hydrolysate samples were diluted $1: 10$ and $20 \mu \mathrm{L}$ samples were analyzed by reverse phase $(\mathrm{C} 18)$
HPLC-high resolution/accurate tandem mass spectrometry (HPLC-MS/MS). Peak areas of peaks matching in retention times and accurate mass $\pm 10 \mathrm{ppm}$ MS/MS transitions of authentic reference standards were used to calculate concentrations by comparison to an external standard curve as described previously [18].

\section{Chemical proteomics}

For yeast proteomics, triplicate $10 \mathrm{~mL}$ of YPD $+1 \% \mathrm{GVL}$ or YPD were inoculated with the control strain to a starting $\mathrm{OD}_{600}$ of 0.01 and incubated aerobically at $30^{\circ} \mathrm{C}$ with shaking at $200 \mathrm{rpm} .2 \mathrm{~mL}$ of each culture was harvested when they reached an $\mathrm{OD}_{600}$ of $\sim 0.5$ (mid log phase growth). Cells were pelleted at $10,000 \mathrm{rpm}$, the media removed, and stored at $-80{ }^{\circ} \mathrm{C}$ until processing for proteome analysis.

Yeast cell pellets were resuspended in $6 \mathrm{M} \mathrm{GnHCl}$ (Sigma, St. Louis, MO) with $50 \mathrm{mM}$ Tris pH 8.0 (Sigma, St. Louis, MO), boiled for $5 \mathrm{~min}$, and precipitated by adding methanol (Thermo Fisher Scientific, Pittsburgh, PA) to a final concentration of $90 \%$. The precipitate was centrifuged at 10,000 rcf for $5 \mathrm{~min}$, decanted, and air dried. The protein pellet was resuspended in $8 \mathrm{M}$ urea (Sigma, St. Louis, MO) with $100 \mathrm{mM}$ Tris pH 8.0, $10 \mathrm{mM}$ Tris (2-carboxyethyl) phosphine (Sigma, St. Louis, MO), and $40 \mathrm{mM}$ chloroacetamide (Sigma, St. Louis, MO). The resuspended sample was diluted to $1.5 \mathrm{M}$ urea with $50 \mathrm{mM}$ Tris $\mathrm{pH}$ 8.0. Trypsin was added to a final ratio of 1:20 (enzyme to protein) and the samples were incubated at ambient temperature overnight. Peptides were desalted over Strata-X cartridges (Phenomenex, Torrance, CA). Desalted peptides were dried in a speed vac and resuspended in $0.2 \%$ formic acid (Thermo Fisher Scientific, Rockford, IL). Peptides were quantified with the Pierce quantitative colorimetric peptide assay kit (Thermo Fisher Scientific, Rockford, IL).

For each analysis, $2 \mu \mathrm{g}$ of peptides were separated across a $30 \mathrm{~cm}, 75 \mu \mathrm{m}$ i.d. column packed with $1.7 \mu \mathrm{m}$ BEH C18 particles (Waters, Milford, MA). Mobile phase A was $0.2 \%$ formic acid and B was $0.2 \%$ formic acid, $70 \%$ $\mathrm{ACN}$, and 5\% DMSO (Thermo Fisher Scientific, Pittsburgh, PA). The gradient was 5-50\% B over 100 min followed by a $100 \% \mathrm{~B}$ wash and re-equilibration with $0 \%$ B. Eluted peptides were analyzed on a Thermo Fusion Orbitrap (Thermo Fisher Scientific, San Jose, CA). Orbitrap survey scans were performed at 60,000 resolution, followed by ion-trap $\mathrm{ms} / \mathrm{ms}$ analyses of the most intense precursors (with $\mathrm{z}=2-6$ ) for less than $3 \mathrm{~s}$ and using a dynamic exclusion of $15 \mathrm{~s}$. The maximum injection time for each $\mathrm{ms} / \mathrm{ms}$ was $25 \mathrm{~ms}$ and the ion-trap resolution was set to turbo.

Peptides were identified and quantified from the MS data using the MaxQuant software suite with the 
Andromeda and MaxLFQ search and quantitation algorithms, respectively. Spectra were searched against a Uniprot human proteome and common contaminant database concatenated with the reverse sequences. Match between runs was toggled on with the default settings. Peptide and protein identifications were filtered to $1 \%$ FDR, and proteins were quantified by the MaxLFQ algorithm using the default settings. Data was visualized in Spotfire 5.5.0 (TIBCO, USA). A Bonferroni-corrected hypergeometric distribution test was used to search for significant enrichment of GO terms among the top 15 sensitive/resistant deletion mutants with a $\mathrm{p}$ value of $\mathrm{p}<0.01[15]$.

\section{Ergosterol quantification}

The strains used in this study were Y133 and Y133 pad $1 \Delta f d c 1 \Delta$. Yeasts were cultured aerobically in triplicate $25 \mathrm{~mL}$ of synthetic hydrolysate (SynH) media with and without $1 \%$ GVL and incubated on a rotary shaker at $30{ }^{\circ} \mathrm{C}$ at $225 \mathrm{rpm}$ until an OD600 of 1.0 was reached. The entire culture was sampled without separation of the cells from the culture medium. The results were obtained by a simple method including saponification with methanolic potassium hydroxide, extraction of non-saponified lipids, derivatization and the ergosterol content was compared to an analytical reference standard.

Yeast cultures were diluted to O.D. 0.1-0.3 with SynH. Cultures were saponified by adding methanolic potassium hydroxide to bacterial culture containing cholesterol and deuterated 5 alpha Cholestan as internal standards [20].

Variations of this procedure have been used for many years to extract most lipid classes into essentially nonpolar chloroform solvent [21, 22]. The extraction solvent (methanol:chloroform) was added to the hydrolyzed culture sample and the original sample tube was rinsed with water and transferred to a separation funnel. Two phases were observed and the lower phase (chloroform) containing the lipids was collected. The original sample tube was rinsed with chloroform and transferred to the separation funnel and the phases were allowed to separate. The lower phase was added to the initial collected chloroform phase and the upper phase was discarded. The total sample volume collected was dried in a heat block under a gentle stream of nitrogen.

Chloroform was added to all dried sample and standard tubes, mixed and aliquoted for derivatization. N-Methyl$\mathrm{N}$-(trimethylsilyl) trifluoroacetamide (MSTFA, Sigma, USA) and anhydrous pyridine were added to all samples and standards, heated, cooled, and transferred to an autosampler vial and were immediately analyzed.

Ergosterol standards with a calibration range of $0.194 \mu \mathrm{g} / \mathrm{mL}$ to $396.65 \mu \mathrm{g} / \mathrm{mL}$ were derivatized with
MSTFA and anhydrous pyridine. Cholesterol and deuterated 5 alpha Cholestan were used as internal standards, and added to all standard levels.

Samples were analyzed on an Agilent technologies 5975C inert XL MSD with Triple-Axis Detector and an Agilent Technologies 7890A gas chromatograph coupled with a CTC Analytics COMBIPAL Autosampler.

The primary column was HP-5MS 5\% Phenyl Methyl Silox: $30 \mathrm{~m} \times 250 \mu \mathrm{m} \times 0.25 \mu \mathrm{m}$. Carrier Gas was He, $1.2 \mathrm{~mL} / \mathrm{min}$ with an Inlet temperature of $150^{\circ} \mathrm{C}$. Primary GC oven program: initial temp of $1500^{\circ} \mathrm{C}$, hold for $1 \mathrm{~min}$; increase $40{ }^{\circ} \mathrm{C} / \mathrm{min}$ to $280{ }^{\circ} \mathrm{C}$ and hold for $0 \mathrm{~min}$ then $5{ }^{\circ} \mathrm{C} / \mathrm{min}$ to $320^{\circ} \mathrm{C}$ for $1 \mathrm{~min}$, Deactivated glass split universal liner with glass wool, split ratio 10:1, Quad temp $150{ }^{\circ} \mathrm{C}$, Source temp $230{ }^{\circ} \mathrm{C}$. Integration of peak areas, calculation of standard curves and interpolation of concentrations were performed with vendor supplied software; MassHunter Workstation Software B.06.00.

\section{Results}

GVL is the primary inhibitor found in GVL hydrolysates

GVL-produced hydrolysates remain largely unstudied; thus, our first goal was to identify the primary inhibitors of GVL hydrolysates. LC/MS of hydrolysates revealed that three inhibitory compounds were highly abundant in the GVL hydrolysates: GVL, levulinic acid, and hydroxymethylfurfural (HMF); other lignocellulosic derived inhibitors were present, but at much lower concentrations (Additional file 1). GVL hydrolysates can contain a high level of residual GVL ( $250 \mathrm{mM})$; at this level, GVL is the most abundant inhibitor in GVL hydrolysates with half-maximal inhibitory concentration $\left(\mathrm{IC}_{50}\right)$ of $270 \mathrm{mM}$ (Fig. 1). Based on this result, we focused on understanding GVL toxicity and developing a tolerant yeast strain.

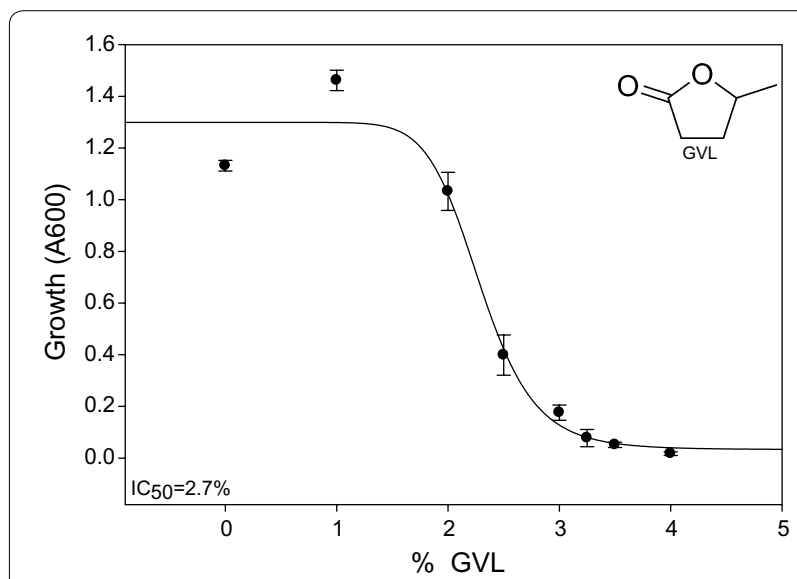

Fig. 1 Production of GVL hydrolysates and toxicity. The half-maximal inhibitory concentration $\left(\mathrm{IC}_{50}\right)$ of $\mathrm{GVL}$ against our control strain in rich media was estimated using an $8 \mathrm{pt}$ dose curve (Mean $\pm \mathrm{SE}, \mathrm{n}=3$ ) 


\section{Chemical genomic predicts GVL targets cellular membranes and membrane-bound processes}

To understand the mode of action of GVL toxicity we conducted chemical genomic analysis. This is a reverse genetics method that uses collections of defined gene mutants, and uses the response of these mutants in the presence of a chemical stress to gain functional insight into the chemical's mode of action and cellular target [23]. We first tested the yeast deletion collection with standard rich medium with $2 \%$ galactose (YP-Gal) containing 2.3\% GVL and used barcode sequencing to identify the fitness response of the individual deletion mutants. This assay uses the barcoded, yeast deletion collection challenged against an inhibitory compound, by monitoring the relative abundance of mutant strains via their unique molecular barcodes versus a control solvent, biological pathways sensitive to the compound can be identified, yielding prediction of the compound's mode of action (See reviews [24, 25]). Further, deletion mutants resistant to the compound provide potential points of engineering tolerance [8].

We identified 843 significantly responsive deletion mutants ( $<<0.01$, Additional file 2). Among the top 10 sensitive deletion mutants, we found significant enrichment for genes involved in late endosome to vacuole transport ( $\mathrm{p}<0.01$, Fig. 2a), driven by deletion mutants of SEC28, VPS38, DID2. We validated the mutants within this Gene Ontology (GO) category by testing single mutants individually, and found all gave a lower $\mathrm{IC}_{50}$ compared to the control strain (Fig. 2b). Deletion mutants of these 3 genes exhibit increased sensitivity to ethanol, heat, the ionophore nigericin, and the ergosterol biosynthesis inhibitor miconazole [26-31]. When we correlated the chemical genomic profile of GVL with the yeast genetic interaction network database [32], we found significant enrichment for genes involved in golgi-vesicle mediated transport among the top 10 correlations $(\mathrm{p}=0.001)$. RET2 was consistently predicted as the top correlation for the GVL chemical genomic profile. Ret2p is a subunit of the coatomer complex involved in retrograde transport between Golgi and ER is also involved in golgi transport of vesicles [33]. RET2 mutants similarity show increased sensitivity to heat and membrane disrupting agents [26, 28]. We correlated the chemical genomic profile of GVL to existing chemical genomic datasets [23], and found its profile was significantly similar to profiles of the ionophore nigericin $(\mathrm{p}<0.01)$ and the phosphatidylserine targeting agent papuamide $(\mathrm{p}<0.01)$, [23]. Taken together, these data suggest GVL could exert toxicity by damaging membrane integrity.

\section{GVL damages membranes and is synergistic with ethanol}

To confirm if GVL treatment can rapidly affect cell integrity, we assessed cell permeability after GVL treatment. Using flow cytometry combined with a dye that is only taken up by cells with damaged membranes, we found a rapid and dose dependent effect of GVL on permeability (Fig. 3a, b), similar to the effects of ethanol but with a greater magnitude (Fig. 3b). Given that both GVL and
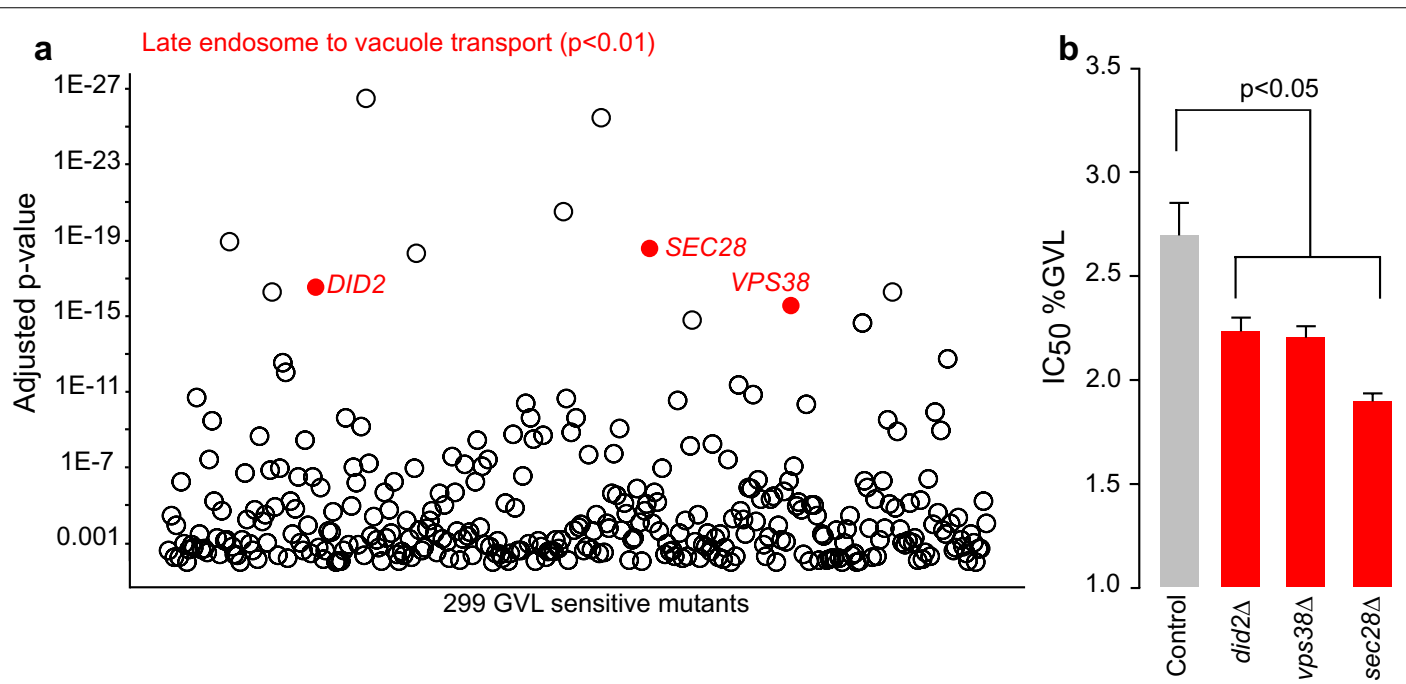

Fig. 2 Chemical genomic profiling of GVL. Chemical genomic profiling of the yeast non-essential deletion mutant collection was used to identify mutants significantly sensitive to GVL $(\mathbf{a}, n=3)$. The $p$-value of mutants with a decreased fitness in the presence of $2.3 \% \mathrm{GVL}$ compared to blank medium is plotted on the Y-axis. Of the top 20 significantly responsive mutants, strains annotated to the GO process Late Endosome to Vacuole Transport (GO:0045324) are presented in red. The GVL IC 50 of did2 $\triangle$, vps38 $\triangle$, and sec28 $\triangle$ versus the control strain was estimated in rich medium (b Mean $\pm S E, n=3)$. ANOVA was used to detect differences in growth 

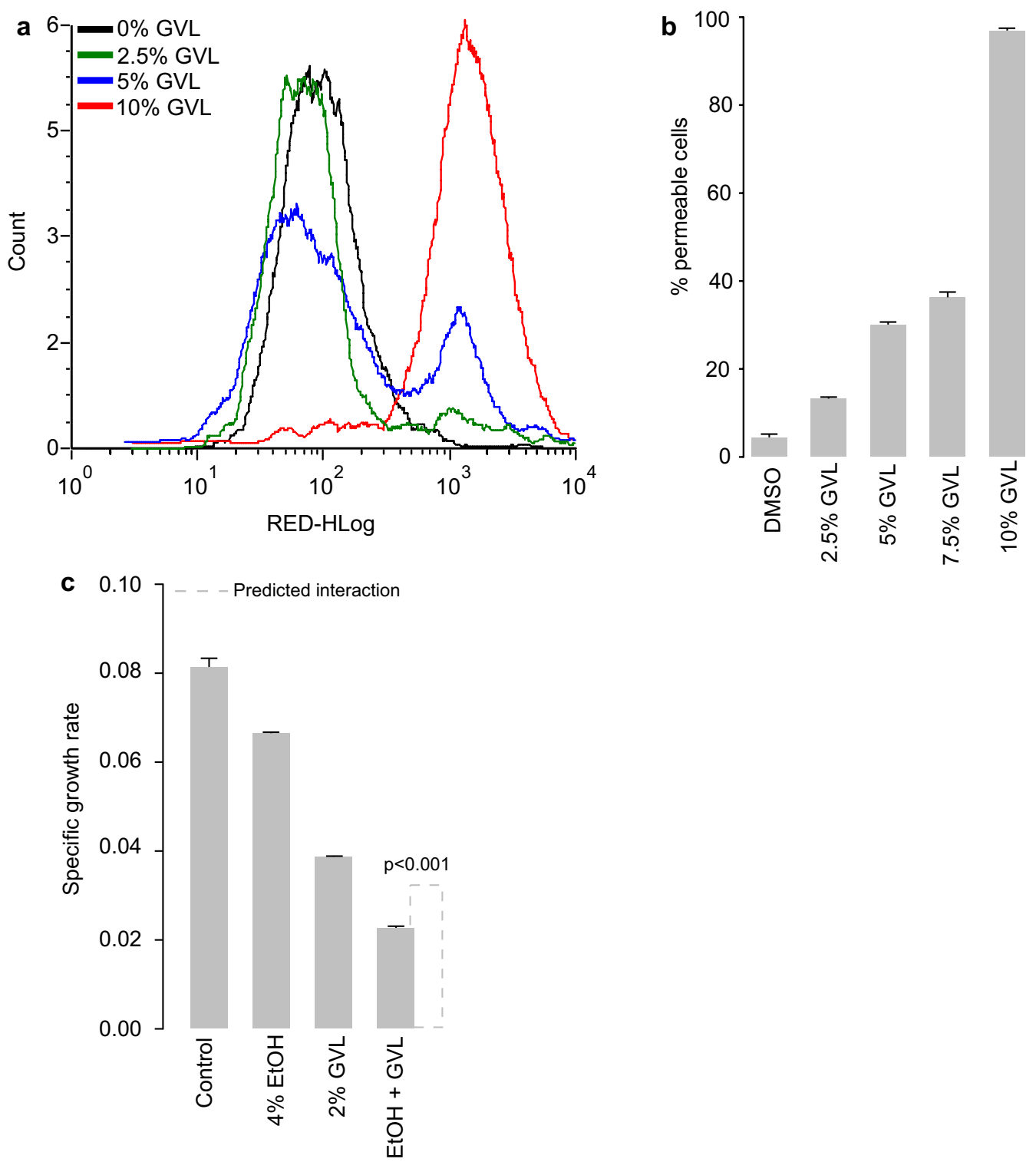

Fig. 3 The effects of GVL on cell permeability and synergism with ethanol. Cells were treated with GVL for $4 \mathrm{~h} \mathrm{GVL}$, then incubated with a dye that is only taken up by cells with compromised membrane integrity, which results in increased red fluorescence (a). The percent of permeable cells in populations of cells treated with either $\mathrm{GVL}$ or $\mathrm{EtOH}$ (b Mean $\pm \mathrm{SE}, \mathrm{n}=3$ ). Specific growth rate of cells treated with $2 \% \mathrm{GVL}, 4 \% \mathrm{EtOH}$, or a combination of both (c Mean $\pm S E, n=3$ ), the dashed line indicated the predicted level of inhibition if $G V L$ and EtOH were additive in their toxicities

ethanol can damage cellular membranes, we also tested if these compounds are synergistic. We found a strong synergism between GVL and ethanol in both our lab strain and xylose fermenting strain (Fig. 3c). At a $2 \%$ GVL concentration and $4 \%$ ethanol concentration, we observed significant synergism in membrane damage between GVL and ethanol $(\mathrm{p}<0.01)$. This suggest that as ethanol titers increase during fermentation, the toxic effects of GVL and ethanol will magnify each other, which ultimately will affect yield.

\section{Deletion of PAD1 and FDC1 enhance GVL tolerance}

Importantly for our goal, we also investigated gene deletions that increased resistance to GVL. Among the top GVL-resistant mutants we found a significant enrichment for genes involved in phenylpropanoid metabolic process ( $\mathrm{p}<0.002$, Fig. 4a), driven by deletion mutants of $P A D 1$ and $F D C 1$. Single mutant validations reveal deletion of these genes improved GVL tolerance (Fig. 4b). Pad1p is responsible for generating a co-factor needed by Fdc1p to decarboxylate phenolic acids [34-36]. 

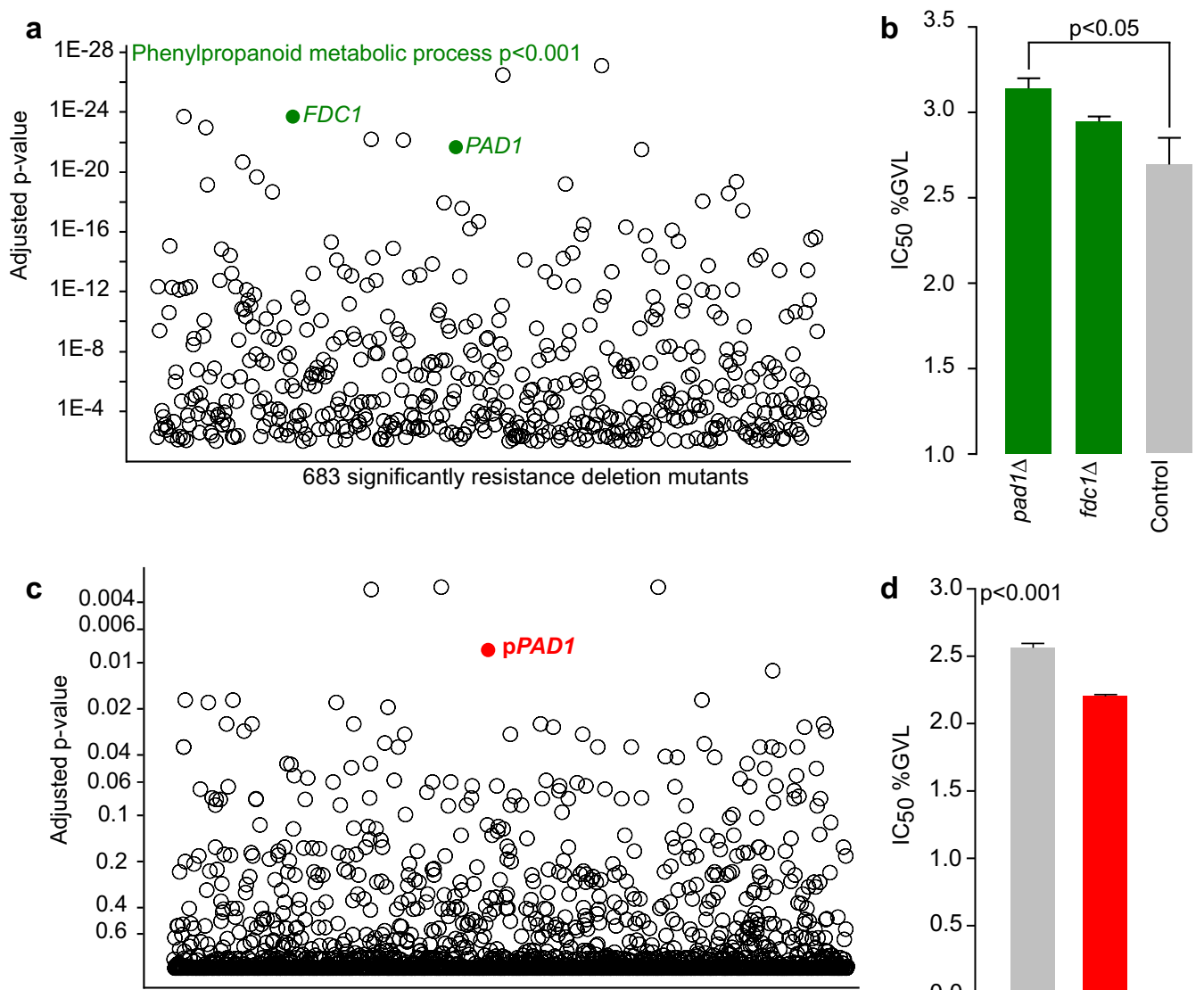

2228 sensitive overexpression mutants in $\mathrm{Y} 133$

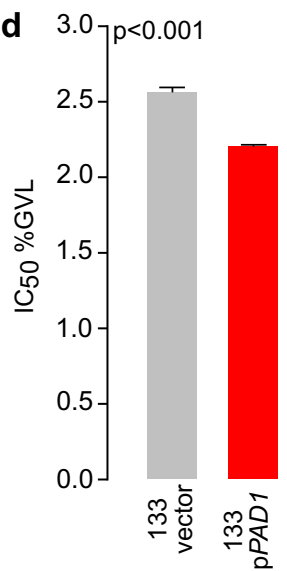

Fig. 4 Identifying genes mediating GVL toxicity by deletion and overexpression mutant profiling. The p-value of mutants with an increased fitness in the presence of $2.3 \% \mathrm{GVL}$ compared to blank medium is plotted on the $Y$-axis $(\mathbf{a} n=3)$. Of the top 20 significantly responsive mutants, strains annotated to the GO process Late Phenylpropanoid metabolic process (GO:0009698) are presented in green. GVL IC 50 values of padi $\triangle$ and fdc $1 \triangle$ versus the control strain (b Mean $\pm \mathrm{SE}, \mathrm{n}=3$ ). Using the xylose fermenting yeast $\mathrm{Y} 133$ transformed with the $2 \mu$ barcoded plasmid collection (MoBY 2.0), we identified genes that confer GVL sensitivity when overexpressed $(\mathbf{c}, n=3)$. The $p$-value of overexpression mutants with a decreased fitness in the presence of $2.3 \%$ GVL compared to blank medium is plotted on the Y-axis, and the strain harboring PPAD1 is highlighted in red. GVL IC50 values of $\mathrm{pPAD} 1$ versus an empty vector $(\mathbf{d}$, Mean $\pm \mathrm{SE}, \mathrm{n}=3$ )

\section{Overexpression of PAD1 enhances GVL toxicity}

We wanted to extend our chemical genomic analysis to an industrially relevant, xylose ferment yeast strain. At present, there are no available genome-wide deletion mutant collections in industrial yeast, so we took a complementary approach using overexpression plasmids that could be introduced to any yeast. The MoBY-ORF 2.0 plasmid collection, which encodes barcoded versions of $95 \%$ of all $S$. cerevisiae genes each expressed on a $2 \mu$ plasmid [37], enabled this approach. This collection of plasmids can be pooled and transformed into any yeast to allow investigations of the effect of gene dose under stress conditions. We transformed a version of the xylose-fermenting yeast Y133 [38] en masse with the pooled plasmid collection and selected over $50 \mathrm{~K}$ individual transformants $(10 \times$ genome coverage). We grew this pooled transformant collection in the presence of $2.5 \% \mathrm{GVL}$ or a water control under anaerobic conditions in glucose/xylose-containing media and assessed the effects of increased gene dose on growth in the presence of GVL. We found the PAD1 overexpression mutant was one of the top sensitive strains ( $\mathrm{p}<0.01$, Fig. $4 \mathrm{c}$ ). We confirmed with single mutant cultures that overexpression of $P A D 1$ causes GVL sensitivity. The $\mathrm{IC}_{50}$ of $\mathrm{Y} 133+\mathrm{p} P A D 1$ was $2.2 \%$, compared to $2.56 \%$ of vector control (Fig. $4 \mathrm{~d}$, p $<0.001$ ).

\section{Deletion of PAD1 and FDC1 in a xylose-fermenting strain confers GVL tolerance}

Chemical genomic profiling and validation of individual mutants confirmed that the Pad1p and Fdc1p were 
involved in GVL toxicity. Because pad1 $1 \Delta$ and $f d c 1 \Delta$ deletion mutants both appeared as sensitive in the chemical genetic assay, and because these are functionally related genes, we reasoned that deletion of both genes could have an additive effect on GVL tolerance. We chose to engineer these deletions into a xylose-fermenting yeast strain Y133. PAD1 and FDC1 are adjacent on chromosome IV, and as such we were able to delete both genes at the same time using a single transformation with a PCR product of the antibiotic resistance marker KanMX flanked by homologous regions upstream of $P A D 1$ and downstream of FDC1 (Fig. 5a). We confirmed deletion of both genes by PCR (Fig. 5b).

The $\mathrm{IC}_{50}$ concentration of GVL for the Y133 pad1A $f d c 1 \Delta$ strain was significantly higher than for the Y133 parent (Fig. 5c, p < 0.01). We tested for GVL tolerance in flask experiments under anaerobic and aerobic conditions in both rich and defined media (Additional file 3a-d). In all conditions, the Y133 pad1 $\Delta$ fdc1 $1 \Delta$ mutant had greater growth than the Y133 strain. Additionally, the tolerant strain had greater initial glucose/xylose use, and ethanol production under anaerobic conditions. Finally, we tested the performance of the Y133 pad1s $f d c 1 \Delta$ strain in a scaled-up fermentation experiment, under industrially relevant anaerobic conditions in a synthetic hydrolysate containing 1.5\% GVL. The engineered grew, consumed sugar, and produced significantly more ethanol after $24 \mathrm{~h}$, and had consumed significantly more xylose after $28 \mathrm{~h}(\mathrm{p}<0.05)($ Fig. $5 \mathrm{~d})$.

\section{Chemical proteomics reveals over production of ergosterol genes in response to GVL in the $Y 133$ pad1 $1 \Delta$ fdc1 1 background}

To further understand the mechanism of GVL tolerance of the Y133 pad1 $f d c 1 \Delta$ strain, we used quantitative proteomics to identify how GVL treatment alters protein abundance in the Y133 and Y133 pad1 1 fdc1 1 strain (Additional file 4). Among the top 20 proteins that had increased abundance in the Y133 pad1 $1 \mathrm{fdc1 \Delta}$ versus the Y133 background (Fig. 6a), we observed a significant enrichment for proteins involved in ergosterol (Erg11p, Erg5p, Hmg1p, $\mathrm{p}=0.009$ ). Interestingly, among the top 20 proteins that had decreased abundance in the presence of GVL (Fig. 6a), the Y133 pad1 $1 \Delta d c 1 \Delta$ strain had significantly enrichment in for genes involved in protein folding (Hsp26p, Hsp82p, Fes1p, Sse2p, Ssa3p, Ssa4p; $p=9.2 e^{-5}$ ), which suggests GVL may further exert toxicity by affecting protein folding in non-resistant strains.

\section{Y133 pad $1 \Delta f d c 1 \Delta$ accumulates more ergosterol in response to GVL}

Ergosterol is a fungal membrane sterol that determines membrane fluidity, and by extension can affect thermal tolerance and tolerance of solvents such as ethanol [39]. Given that proteins involved in ergosterol biosynthesis have increased abundance in the Y133 pad1 1 fdc1 $\Delta$ strain compared to the background, we wanted to test in the engineered, GVL-tolerant strain had greater ergosterol content than the parent strain. In untreated $\mathrm{SynH}$ medium, the engineered strain accumulated significantly more ergosterol compared to the parent strain under aerobic conditions (Fig. 6b). This difference was magnified in the presence of $1 \% \mathrm{GVL}$, where the engineered strain significantly increased ergosterol production, whereas the parent strain had decreased ergosterol content (Fig. 6b).

\section{Discussion}

Using chemical genetics, we discovered that deletion of the functionally related genes $P A D 1$ and $F D C 1$ genes confers resistance to GVL in a xylose-fermenting yeast strain, presumably by increasing ergosterol production or ergosterol uptake. Over expression of these genes have been shown to confer resistance to the lignocellulosederived inhibitors cinnamic acid and ferulic acid [40-42] Considering this result, yeast harboring $P A D 1 / F D C 1$ overexpression systems may be incompatible with GVLproduced hydrolysates, and the biocatalyst used should be tailored to the hydrolysate to minimize the effects of process-derived inhibitors (e.g., GVL, ionic liquids), lignocellulose derived inhibitors (e.g., phenolic acids), and end-product inhibitors (e.g., ethanol, isobutanol).

Little is known about the functions of $P A D 1$ and $F D C 1$ in yeast, aside from their role in detoxifying aromatic carboxylic acids in lignocellulosic hydrolysates. The bacterial homologs $u b i X$ and $u b i D$ are known to function in ubiquinone biosynthesis. PAD1 has a significant negative genetic interaction with $C O Q 2$, the second step of ubiquinone biosynthesis [43]. Recent work has revealed that $P A D 1$ is not a decarboxylase as originally described, but rather synthesizes a novel co-factor (a prenylated flavin) required for the decarboxylase activity of $F D C 1$ [34-36]. PAD1 and FDC1 may function in ubiquinone biosynthesis [44], but they are not essential to the process [41].

The relationship between PAD1/FDC1 and ergosterol content also remains unclear. Ubiquinone and ergosterol share the same precursors, as both are products of the mevalonate pathway [45]. Deletion of PAD1 could reduce flux towards ubiquinone biosynthesis, resulting in greater availability of ergosterol biosynthetic precursor, or induce increased sterol uptake. Additionally, $F D C 1$ has the most similar genetic interaction profile as $Y M L 082 C$, which is regulated by UPC2 (a gene involved in sterol uptake and biosynthesis) via an upstream sterol response element [43, 46]. Our results are consistent with previous studies that found the laboratory 

pad1 $1 \Delta$

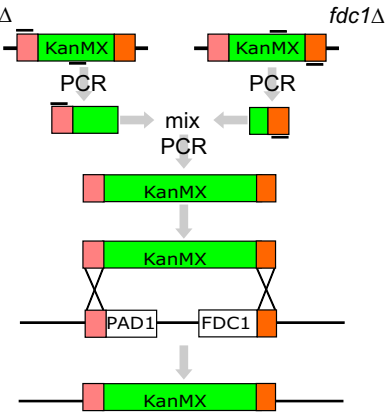

b

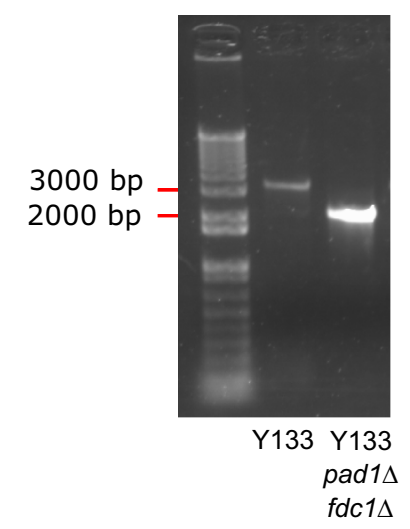

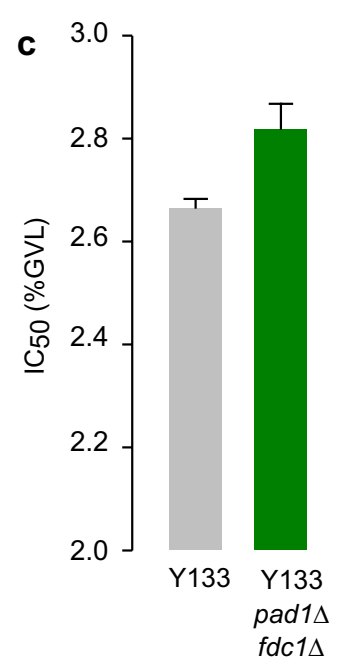

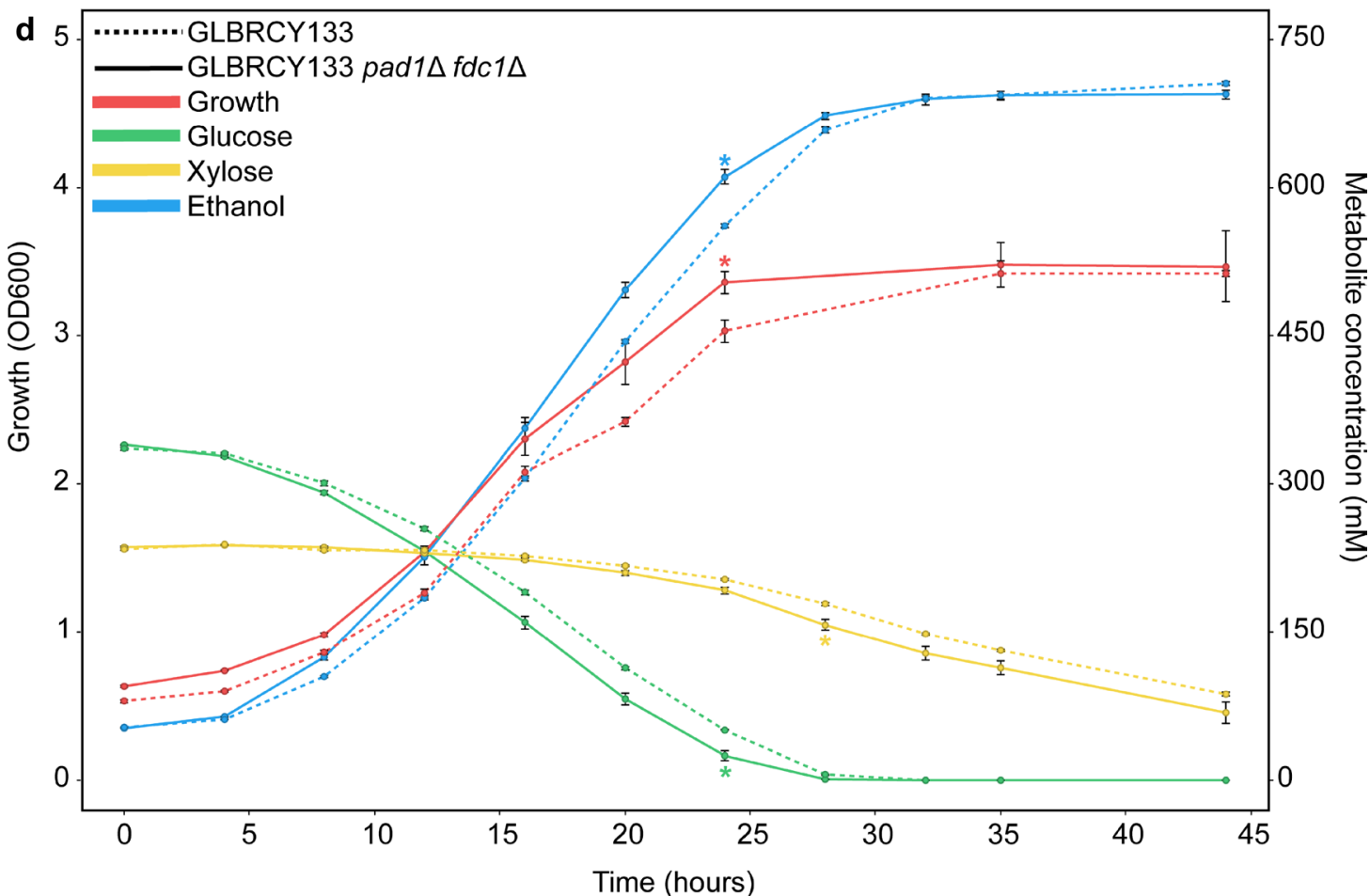

Fig. 5 Deletion of PAD1 and FDC1 and the effect of this modification on GVL tolerance in a xylose fermenting yeast. We used a two-step PCR approach to simultaneously delete PAD1 and FDC1 in Y133, which are adjacent on chromosome IV (a), and confirmed deletion by PCR (b). GVL IC50 values of $\mathrm{Y} 133$ pad1 $\triangle \mathrm{fdc} 1 \triangle$ versus $\mathrm{Y} 133$ (c) Mean $\pm \mathrm{SE}, \mathrm{n}=3$ ). Growth, sugar consumption, and ethanol production of $\mathrm{Y} 133$ pad1 $\triangle$ fdc $1 \triangle$ versus Y133 in synthetic hydrolysate medium containing $1.5 \% \mathrm{GVL}$ under anaerobic conditions (d, Mean $\pm \mathrm{SE}, \mathrm{n}=3$ ). ${ }^{*}$ Indicates where the engineered strain has significantly greater growth or ethanol production, or significantly less remaining sugars $(p<0.05)$

strain CEN.PK113-7D harbored a loss of function mutation (TAT $\rightarrow$ TAG, Stop codon) in PAD1, and that this strain contained more ergosterol during logarithmic growth [47]. CEN.PK113-7D also harbored mutations in the ergosterol biosynthetic genes HMG1, ERG8, and
$E R G 9$, and it is not known if these mutations were secondary to the PAD1 loss-of-function mutation. Our proteomic analysis revealed the pad $1 \Delta / f d c 1 \Delta$ mutant had increased abundance of Hmg1p, Erg5p, and Erg11p in the presence of GVL (Fig. 6a). Given that ergosterol 


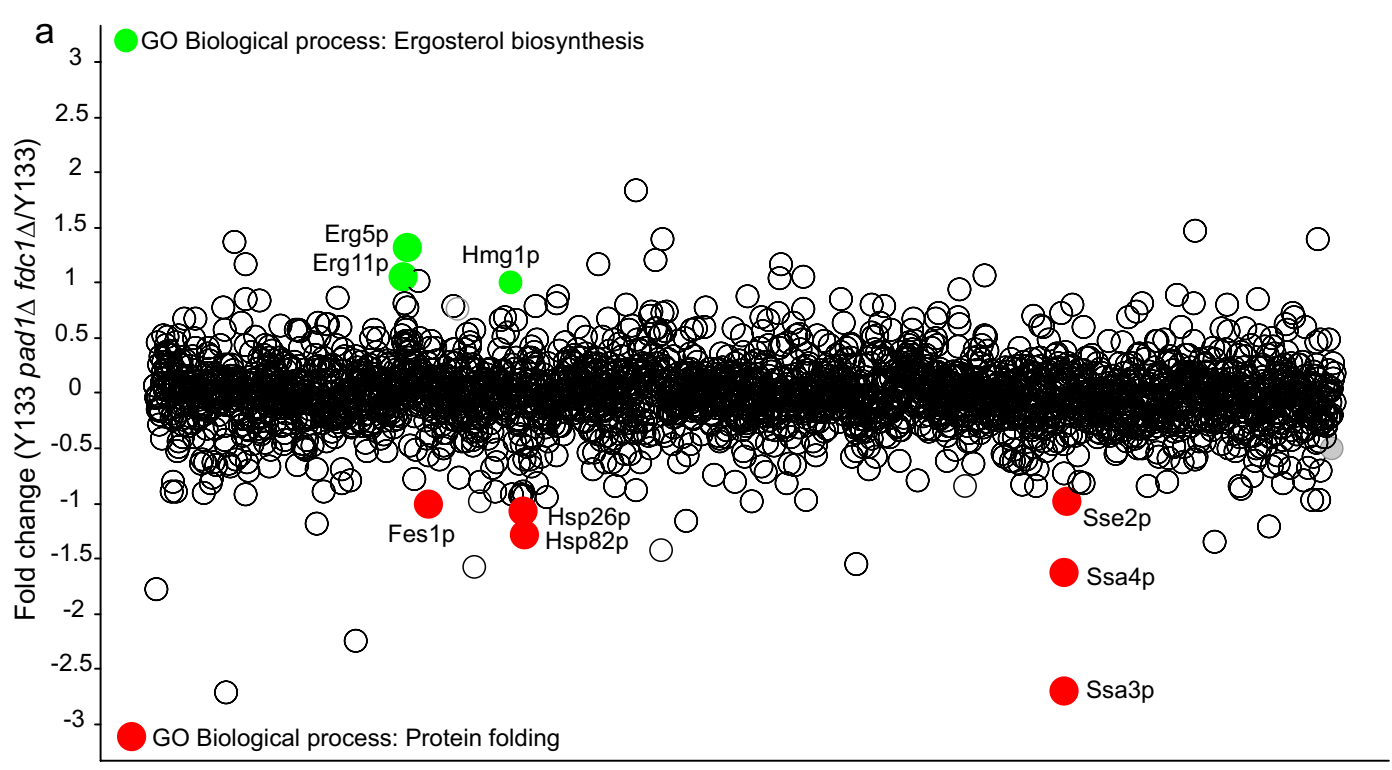

b

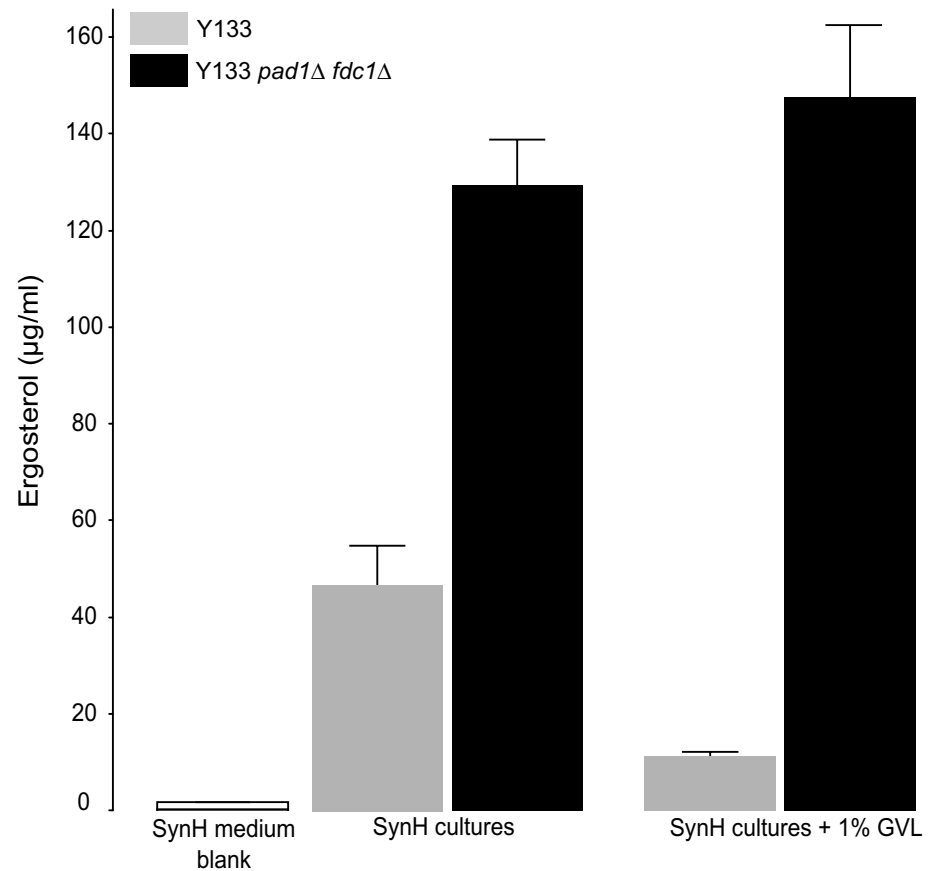

Fig. 6 Chemical proteomics and ergosterol quantification for $Y 133$ and $Y 133$ pad $1 \Delta$ and $f d c 1 \Delta$. Protein abundance changes of $Y 133$ pad $1 \Delta$ fdc $1 \Delta$ versus $\mathrm{Y} 133$ in the presence of $1 \% \mathrm{GVL}(\mathbf{a}, n=3)$. Fold change values are presented on the $Y$-axis. Proteins that had increased abundance in the Y133 pad1 $\triangle \mathrm{fdc} 1 \triangle$ strain compared to Y133 that are annotated to Ergosterol biosynthesis (GO:0006696) are highlighted in green. Proteins that had decreased abundance in the Y133 pad1 $\triangle \mathrm{fdc} 1 \Delta$ strain compared to Y133 that are annotated to Protein folding (GO:0006457) are highlighted in red. Total cellular ergosterol quantification of $\mathrm{Y} 133$ pad $1 \triangle \mathrm{fdc} 1 \triangle$ and $\mathrm{Y} 133$ grown aerobically $\pm 1 \% \mathrm{GVL}(\mathbf{b}$, Mean $\pm \mathrm{SE}, \mathrm{n}=3$ )

biosynthesis is oxygen dependent, and GVL tolerance is apparent in both aerobic and anaerobic media (Fig. 5d, Additional file 3), deletion of PAD1 and FDC1 may lead to sterol uptake and/or biosynthesis, but sterol uptake would explain tolerance in anaerobic conditions. Further work is needed to more completely characterize the relationship between $P A D 1 / F D C 1$ and sterol content in yeast. 


\section{Conclusions}

We have elucidated the mechanism of GVL toxicity in $S$. cerevisiae. Like ethanol, the non-polar solvent GVL compromises membrane integrity, leading to cell lysis. Further, GVL is synergistic with ethanol in toxicity, thus reducing the amount of residual GVL in GVL-produced hydrolysates is critical for not only GVL recovery economics, but also ensuring maximum ethanol titers during fermentation. Given the general effects of GVL on membranes, it is likely that this mechanism of toxicity is similar in prokaryotic biocatalysts.

\section{Additional files}

Additional file 1. GVL hydrolysate inhibitors.

Additional file 2. Chemical genomic profile of GVL.

Additional file 3. Growth, sugar consumption, and ethanol production of $Y 133$ pad1 1 fdc1 $\Delta$ vs $Y 133$ grown in anaerobic and aerobic conditions with either rich media (YPXD) or synthetic hydrolysates $(n=3$, Mean $\pm \mathrm{SE}$ ).

Additional file 4. Proteomic profile of $Y 133$ pad1 1 fdc $1 \Delta$ vs $Y 133$ grown in YPD medium plus $1 \%$ GVL.

\section{Abbreviations}

GVL: gamma valerolactone; YPD: yeast extract peptone dextrose; $\mathrm{SynH}$ : synthetic hydrolysate; DMSO: dimethyl sulfoxide.

\section{Authors' contributions}

$\mathrm{QD}, \mathrm{SB}, \mathrm{LH}, \mathrm{AH}$, JP performed experiments. RL designed experiments and edited the manuscript. CLM developed software for analysis. AH, and JC performed proteomics and analysis. JS, DX and YZ performed large-scale fermentation. $\mathrm{AH}$ and $\mathrm{MM}$ provided ergosterol quantification and analysis of GVL hydrolysates. JP designed experiments, performed analysis, and wrote the manuscript. All authors read and approved the final manuscript.

\section{Author details}

${ }^{1}$ Great Lakes Bioenergy Research Center, University of Wisconsin-Madison, 1552 University Ave, Madison, WI, USA. ${ }^{2}$ Present Address: Lehrstuhl für Chemie Biogener Rohstoffe, Technische Universität München, Schulgasse 16, 94315 Straubing, Germany. ${ }^{3}$ School of Biology, Georgia Institute of Technology, Atlanta, GA, USA. ${ }^{4}$ University of Wisconsin Biotechnology Center, Madison, WI, USA. ${ }^{5}$ Department of Biomolecular Chemistry, University of Wisconsin-Madison, Madison, WI, USA. ${ }^{6}$ Morgridge Institute for Research, Madison, WI, USA. ${ }^{7}$ Department of Chemistry, University of Wisconsin-Madison, Madison, WI, USA. ${ }^{8}$ Genome Center of Wisconsin, Madison, WI, USA.

${ }^{9}$ Department of Computer Science and Engineering, University of MinnesotaTwin Cities, Minneapolis, MN, USA. ${ }^{10}$ Present Address: Yumanity Therapeutics, 790 Memorial Drive, Suite 2C, Cambridge, MA 02139, USA.

\section{Acknowledgements}

We thank Jim Dumesic and Jeremy Luterbacher for providing samples of GVL hydrolysates and Charles Boone for providing the yeast deletion collection and the MoBY-ORF 2.0 collections. We thank Trey Sato for critical discussions of this work. The authors thank the University of Wisconsin Biotechnology Center DNA Sequencing Facility for providing sequencing facilities and services.

\section{Competing interests}

The authors declare that they have no competing interests.

\section{Availability of data and materials}

Chemical genomic and chemical proteomic data generated or analyzed during this study are included in this published article as additional information.
Consent for publication

Not applicable.

\section{Ethics approval and consent to participate}

Not applicable.

\section{Funding}

This work was funded by the DOE Great Lakes Bioenergy Research Center (DOE BER Office of Science DE-FC02-07ER64494). CM is supported by Grants from the National Institutes of Health (1R01HG005084-01A1, 1R01GM10497501, R01HG005853), a Grant from the National Science Foundation (DBI 0953881).

\section{Publisher's Note}

Springer Nature remains neutral with regard to jurisdictional claims in published maps and institutional affiliations.

Received: 11 May 2017 Accepted: 14 December 2017

Published online: 12 January 2018

References

1. Palmqvist $E$, Hahn-Hägerdal B. Fermentation of lignocellulosic hydrolysates. II: inhibitors and mechanisms of inhibition. Bioresour Technol. 2000;74:25-33.

2. Piotrowski JS, Zhang Y, Bates DM, Keating DH, Sato TK, Ong IM, et al. Death by a thousand cuts: the challenges and diverse landscape of lignocellulosic hydrolysate inhibitors. Front Microbiol. 2014;5. http://www.ncbi. nlm.nih.gov/pmc/articles/PMC3954026/. Accessed 10 Apr 2014

3. Keating DH, Zhang Y, Ong IM, Mcllwain S, Morales EH, Grass JA, et al. Aromatic inhibitors derived from ammonia-pretreated lignocellulose hinder bacterial ethanologenesis by activating regulatory circuits controlling inhibitor efflux and detoxification. Microb Physiol Metab. 2014;5:402.

4. Luterbacher JS, Rand JM, Alonso DM, Han J, Youngquist JT, Maravelias CT, et al. Nonenzymatic sugar production from biomass using biomassderived $\gamma$-valerolactone. Science. 2014;343:277-80.

5. Socha AM, Parthasarathi R, Shi J, Pattathil S, Whyte D, Bergeron M, et al. Efficient biomass pretreatment using ionic liquids derived from lignin and hemicellulose. Proc Natl Acad Sci. 2014;111:E3587-95.

6. Docherty KM, Charles F, Kulpa J. Toxicity and antimicrobial activity of imidazolium and pyridinium ionic liquids. Green Chem. 2005;7:185-9.

7. Ouellet M, Datta S, Dibble DC, Tamrakar PR, Benke PI, Li C, et al. Impact of ionic liquid pretreated plant biomass on Saccharomyces cerevisiae growth and biofuel production. Green Chem. 2011;13:2743.

8. Dickinson Q, Bottoms S, Hinchman L, Mcllwain S, Li S, Myers CL, et al. Mechanism of imidazolium ionic liquids toxicity in Saccharomyces cerevisiae and rational engineering of a tolerant, xylose-fermenting strain. Microb Cell Fact. 2016;15:17.

9. Bukhman YV, DiPiazza NW, Piotrowski J, Shao J, Halstead AGW, Bui MD, et al. Modeling microbial growth curves with GCAT. BioEnergy Res. 2015;8:1022-30.

10. Piotrowski JS, Simpkins SW, Li SC, Deshpande R, Mcllwain SJ, Ong IM, Myers CL, Boone C, Andersen RJ. Chemical genomic profiling via barcode sequencing to predict compound mode of action. In: Hempel J, Williams C, Hong C (eds) Chemical biology. Methods in molecular biology, vol 1263. New York, NY: Humana Press; 2015.

11. Piotrowski JS, Li SC, Deshpande R, Simpkins SW, Nelson J, Yashiroda Y, et al. Functional annotation of chemical libraries across diverse biological processes. Nat Chem Biol. 2017;13:982-93.

12. Simpkins SW, Nelson J, Deshpande R, Li SC, Piotrowski JS, Wilson EH, et al. Large-scale interpretation of chemical-genetic interaction profiles using a genetic interaction network. bioRxiv. 2017;111252. https://doi. org/10.1101/111252

13. Robinson MD, McCarthy DJ, Smyth GK. edgeR: a Bioconductor package for differential expression analysis of digital gene expression data. Bioinforma Oxf Engl. 2010;26:139-40.

14. Robinson DG, Chen W, Storey JD, Gresham D. Design and analysis of barseq experiments. G3 Genes Genomes Genet. 2014;4:11-8. 
15. Boyle El, Weng S, Gollub J, Jin H, Botstein D, Cherry JM, et al. GO:TermFinder-open source software for accessing gene ontology information and finding significantly enriched gene ontology terms associated with a list of genes. Bioinformatics. 2004;20:3710-5.

16. Ho CH, Magtanong L, Barker SL, Gresham D, Nishimura S, Natarajan P, et al. A molecular barcoded yeast ORF library enables mode-of-action analysis of bioactive compounds. Nat Biotech. 2009;27:369-77.

17. Sato TK, Tremaine M, Parreiras LS, Hebert AS, Myers KS, Higbee AJ, et al. Directed evolution reveals unexpected epistatic interactions that alter metabolic regulation and enable anaerobic xylose use by Saccharomyces cerevisiae. PLoS Genet. 2016;12:e1006372.

18. Serate J, Xie D, Pohlmann E, Donald C, Shabani M, Hinchman L, et al. Controlling microbial contamination during hydrolysis of AFEX-pretreated corn stover and switchgrass: effects on hydrolysate composition, microbial response and fermentation. Biotechnol Biofuels. 2015;8:180.

19. Piotrowski JS, Okada H, Lu F, Li SC, Hinchman L, Ranjan A, et al. Plantderived antifungal agent poacic acid targets $\beta$-1,3-glucan. Proc Natl Acad Sci. 2015;112:E1490-7.

20. Lamacka M, Sajbidor J. Ergosterol determination in Saccharomyces cerevisiae. Comparison of different methods. Biotechnol Tech. 1997:11:723-5.

21. Bligh EG, Dyer WJ. A rapid method of total lipid extraction and purification. Can J Biochem Physiol. 1959;37:911-7.

22. Axelsson M, Gentili F. A single-step method for rapid extraction of total lipids from green microalgae. PLoS ONE. 2014;9:e89643.

23. Parsons A, Lopez A, Givoni I, Williams D, Gray C, Porter J, et al. Exploring the mode-of-action of bioactive compounds by chemical-genetic profiling in yeast. Cell. 2006;126:611-25.

24. Andrusiak K, Piotrowski JS, Boone C. Chemical-genomic profiling: systematic analysis of the cellular targets of bioactive molecules. Bioorg Med Chem. 2012;20:1952-60.

25. Nislow C, Giaever G. 17 chemical genomic tools for understanding gene function and drug action. Yeast gene anal. 2nd ed. Academic Press; 2007. p. 387-414. http://www.sciencedirect.com/science/article/ B7CV3-4NR6455-P/2/c3224dcbb82e758556950a7650a78600. Accessed 5 Jul 2010.

26. Hoepfner D, Helliwell SB, Sadlish H, Schuierer S, Filipuzzi I, Brachat S, et al. High-resolution chemical dissection of a model eukaryote reveals targets, pathways and gene functions. Microbiol Res. 2014;169:107-20.

27. Vandenbosch D, De Canck E, Dhondt I, Rigole P, Nelis HJ, Coenye T. Genomewide screening for genes involved in biofilm formation and miconazole susceptibility in Saccharomyces cerevisiae. FEMS Yeast Res. 2013:13:720-30

28. Sinha H, David L, Pascon RC, Clauder-Münster S, Krishnakumar S, Nguyen $M$, et al. Sequential elimination of major-effect contributors identifies additional quantitative trait loci conditioning high-temperature growth in yeast. Genetics. 2008;180:1661-70.

29. Ruiz-Roig C, Viéitez C, Posas F, de Nadal E. The Rpd3L HDAC complex is essential for the heat stress response in yeast. Mol Microbiol. 2010;76:1049-62.

30. Auesukaree C, Damnernsawad A, Kruatrachue M, Pokethitiyook P, Boonchird C, Kaneko Y, et al. Genome-wide identification of genes involved in tolerance to various environmental stresses in Saccharomyces cerevisiae. J Appl Genet. 2009;50:301-10.

31. Yoshikawa K, Tanaka T, Furusawa C, Nagahisa K, Hirasawa T, Shimizu H. Comprehensive phenotypic analysis for identification of genes affecting growth under ethanol stress in Saccharomyces cerevisiae. FEMS Yeast Res. 2009:9:32-44

32. Costanzo M, Baryshnikova A, Bellay J, Kim Y, Spear ED, Sevier CS, et al. The genetic landscape of a cell. Science. 2010;327:425-31.

33. Cosson P, Démollière $C$, Hennecke $S$, Duden $R$, Letourneur F. Delta- and zeta-COP, two coatomer subunits homologous to clathrin-associated proteins, are involved in ER retrieval. EMBO J. 1996;15:1792-8.

34. Payne KAP, White MD, Fisher K, Khara B, Bailey SS, Parker D, et al. New cofactor supports a, $\beta$-unsaturated acid decarboxylation via 1,3-dipolar cycloaddition. Nature. 2015;522:497-501.

35. Lin F, Ferguson KL, Boyer DR, Lin XN, Marsh ENG. Isofunctional enzymes PAD1 and UbiX catalyze formation of a novel cofactor required by ferulic acid decarboxylase and 4-hydroxy-3-polyprenylbenzoic acid decarboxylase. ACS Chem Biol. 2015;10:1137-44.

36. White MD, Payne KAP, Fisher K, Marshall SA, Parker D, Rattray NJW, et al. UbiX is a flavin prenyltransferase required for bacterial ubiquinone biosynthesis. Nature. 2015;522:502-6.

37. Magtanong L, Ho CH, Barker SL, Jiao W, Baryshnikova A, Bahr S, et al. Dosage suppression genetic interaction networks enhance functional wiring diagrams of the cell. Nat Biotechnol. 2011;29:505-11.

38. Parreiras LS, Breuer RJ, Avanasi Narasimhan R, Higbee AJ, La Reau A, Tremaine $\mathrm{M}$, et al. Engineering and two-stage evolution of a lignocellulosic hydrolysate-tolerant Saccharomyces cerevisiae strain for anaerobic fermentation of xylose from AFEX pretreated corn stover. PLoS ONE. 2014;9:e107499.

39. Vanegas JM, Contreras MF, Faller R, Longo ML. Role of unsaturated lipid and ergosterol in ethanol tolerance of model yeast biomembranes. Biophys J. 2012;102:507-16.

40. Clausen M, Lamb CJ, Megnet R, Doerner PW. PAD1 encodes phenylacrylic acid decarboxylase which confers resistance to cinnamic acid in Saccharomyces cerevisiae. Gene. 1994;142:107-12.

41. Mukai N, Masaki K, Fujii T, Kawamukai M, lefuji H. PAD1 and FDC1 are essential for the decarboxylation of phenylacrylic acids in Saccharomyces cerevisiae. J Biosci Bioeng. 2010;109:564-9.

42. Richard P, Viljanen K, Penttilä M. Overexpression of PAD1 and FDC1 results in significant cinnamic acid decarboxylase activity in Saccharomyces cerevisiae. AMB Express. 2015;5:12.

43. Costanzo M, VanderSluis B, Koch EN, Baryshnikova A, Pons C, Tan G, et al. A global genetic interaction network maps a wiring diagram of cellular function. Science. 2016;353:aaf1420.

44. Bhuiya MW, Lee SG, Jez JM, Yu O. Structure and mechanism of ferulic acid decarboxylase (FDC1) from Saccharomyces cerevisiae. Appl Environ Microbiol. 2015;81:4216-23.

45. Kuzina V, Domenech C, Cerdá-Olmedo E. Relationships among the biosyntheses of ubiquinone, carotene, sterols, and triacylglycerols in Zygomycetes. Arch Microbiol. 2006;186:485-93.

46. Zavrel M, Hoot SJ, White TC. Comparison of sterol import under aerobic and anaerobic conditions in three fungal species, Candida albicans, Candida glabrata, and Saccharomyces cerevisiae. Eukaryot Cell. 2013;12:725-38.

47. Otero JM, Vongsangnak W, Asadollahi MA, Olivares-Hernandes R, Maury J, Farinelli $L$, et al. Whole genome sequencing of Saccharomyces cerevisiae: from genotype to phenotype for improved metabolic engineering applications. BMC Genom. 2010;11:723. 